\title{
The Reactive Effect of Pretesting in Attitude Change Research: General or Specific?
}

\author{
Joh. Hoogstraten \\ University of Amsterdam
}

In an earlier study it was found that a pretest containing positive statements counteracted the development of negative feelings toward a treatment. The present experiment sought both to replicate the earlier study and to answer an additional question: Is the biasing effect general or is it restricted to pretest content? Again, it appeared that a positive pretest acts as a device to counteract the development of negative sentiments. The effect size, small in the original experiment, was even smaller in the present experiment. Moreover, it was found that the sensitization effect operated only when the pretest and the posttest were identical. Using dissimilar pretest and posttest measures eliminated the biasing effect.

It is widely recognized that the standard pretest-treatment-posttest design raises the problem of a pretest sensitization effect. Nevertheless, measures prior to treatment are frequently used in attitude change research. There are a number of reasons for this preference of pretesting over a randomized design without a pretest (e.g., Christensen, 1977; Lana, 1969).

1. It is sometimes difficult to know for certain that randomization has been successful in providing comparability of subgroups. Pretest mean scores may give the investigator additional confidence.

APPLIED PSYCHOLOGICAL MEASUREMENT

Vol. 4, No. 1 Winter 1980 pp. 39-42

(C) Copyright 1980 West Publishing Co.
2. In order to assure that there is no ceiling effect, it is helpful to pretest subjects to determine if there is enough "room" for the treatment to have an effect.

3. Subjects' initial performance may interact with the effect of the experimental manipulation. For that reason a pretest may be administered to identify subjects' initial position on the dependent variable.

4. The investigator's prime interest may be the success of the treatment in producing change. The pretest-treatment-posttest design provides direct evidence on this issue.

5. If the treatment is spread out over days, weeks, or even months, it must be assumed that the dropout of subjects does not differ in the experimental conditions. Examination of pretest scores can be used to check this assumption of nonselective mortality.

Researchers are thus faced with a difficult dilemma: On the one hand, there are plausible reasons to prefer pretesting, but on the other hand, this may confound the treatment effect. The results of an experiment reported earlier (Hoogstraten, 1979) indicated that the biasing effect of pretesting cannot be neglected. It was shown that a pretest referring to positive treatment aspects counteracted the development of negative feelings; responding to a set of negative pretest statements, on the other hand, did not 
result in less positive reactions than without pretesting. It could not be excluded, however, that the sensitization effect of the positive measure was specific for the information and the topics contained in the pretest, since the same measure was used as pretest and posttest.

The purpose of the experiment to be reported here was twofold. First, it was meant to replicate the earlier experiment, using an identical design and setting and the same measuring instruments. Second, it sought to determine whether the biasing effect found earlier was general or was restricted to particular item content. For that reason the experimental design was appropriately extended.

\section{Method}

Subjects were 203 male and female first-year psychology students at the University of Amsterdam. As part of their course obligations, these freshmen had to participate in a collective testing program lasting 8 days. The first measure used in this study consisted of either a 13-item attitude scale on the test week itself or a control questionnaire of similar length, format, and layout on ecological issues within the laboratory building.

The replication part of the experiment was identical to the earlier experiment. It was undertaken a year later and comprised four conditions. In Condition 1, students responded to the positive $a$ version of the attitude measure (e.g., "The test week is useful") as a pretest and as a posttest. In Condition 3, students completed a parallel $a$ version containing negative statements (e.g., "The test week is not useful"), both as a pretest and a posttest. Students in Conditions 2 and 4 reacted to the control questionnaire as a pretest and completed the appropriate attitude measure as a posttest. This double separate sample pretest-posttest design, which was meant to replicate the earlier study, was extended with two more conditions, as shown in Table 1. It thus became possible to answer the question whether the biasing effect of the pretests is general or item-specific.

In Condition 5, students took a version containing different positive statements as a pretest (b), and in Condition 6 students responded to the negative parallel $b$ version. These versions were constructed for this study. Students in Conditions 5 and 6 completed either a positive or a negative $a$ version as a posttest.

Students were assigned to conditions at random. All items of the attitude measures were of the summated rating format with scale points ranging from 1 (agree) to 7 (disagree). The reactions to positive statements were rescored prior to the statistical analyses; response options agree (1) and disagree (7) were rescored as 7 and 1. A high score thus stood for a positive attitude; and a low score, for a negative attitude.

\section{Results}

The means, standard deviations, and coefficient alpha reliability estimates are given in Table 2. The data indicate that the reliability across times and conditions was about the same, the estimates ranging from .823 to .914 . The outcome of univariate $t$ tests (one-tailed) show

Table 1

Experimental Design

\begin{tabular}{clccc}
\hline Condition & N & Pretest & Treatment & Posttest \\
\hline 1 & 39 & positive $\underline{\mathrm{a}}$ & yes & positive $\underline{\mathrm{a}}$ \\
2 & 30 & no & Yes & positive $\underline{\mathrm{a}}$ \\
3 & 34 & negative $\underline{\mathrm{a}}$ & yes & negative $\underline{\mathrm{a}}$ \\
4 & 32 & no & yes & negative $\underline{\mathrm{a}}$ \\
5 & 37 & positive $\underline{\mathrm{b}}$ & yes & positive $\underline{\mathrm{a}}$ \\
6 & 31 & negative $\underline{\mathrm{b}}$ & yes & negative \\
\hline
\end{tabular}


Table 2

Means and Standard Deviations of Pretest and Posttest Scores of Six Groups

\begin{tabular}{ccccccccc} 
& & \multicolumn{3}{c}{ Pretest } & & \multicolumn{3}{c}{ Posttest } \\
\cline { 2 - 5 } Condition & N & Mean & S.D. & Alpha & & Mean & S.D. & Alpha \\
\hline 1 & 39 & 4.29 & 0.70 & .823 & & 3.71 & 1.19 & .914 \\
2 & 30 & - & - & - & 3.34 & 1.04 & .893 \\
3 & 34 & 4.60 & 0.81 & .840 & & 3.71 & 1.03 & .901 \\
4 & 32 & - & - & - & 3.68 & 0.99 & .887 \\
5 & 37 & 4.12 & 0.93 & .880 & & 3.31 & 1.02 & .863 \\
6 & 31 & 4.30 & 0.74 & .814 & & 3.39 & 1.03 & .890 \\
\hline
\end{tabular}

that students were more negative toward the treatment afterwards than before (Condition 1 : $t=-3.278, d f=38, p<.001$; Condition $3: t=$ $-4.655, d f=33, p<.001$ ). Comparison of pretest means of Conditions 1 and 3 with control posttest means indicated that, as in the earlier experiment, this decrease was not a function of a pretest effect of the first attitude measurement (Pretest 1 versus Posttest $2: t=-4.474, d f=67$, $p<.001$; Pretest 3 versus Posttest $4: t=-4.091$, $d f=64, p<.001)$. Again, it appeared that answering a set of positive statements functioned to inhibit subsequent attitude change (Posttest 1 versus Posttest $2: t=-1.344, d f=67$, $p=.092$ ). However, the effect was less clear than in the earlier study when $p$ was .03 . A pretest effect of the negative attitude measure was clearly absent, both in the earlier study and in the present study (Posttest 3 versus Posttest $4: t$ $=-.119, d f=64$, n.s.).

The second purpose of the experiment was to obtain an answer to the question of the general or specific biasing effect of the positive pretest. Comparison of posttest means of Conditions 1 and 5 and 2 and 5 , respectively, supported an interpretation of an item-specific effect (Posttest 1 versus Posttest $5: t=-1.552, d f=76, p=$ .062 ; Posttest 2 versus Posttest $5: t=.313, d f=$ 65 , n.s.).

\section{Discussion}

The results of the replication part of the experiment were similar to the results of the earlier study. The crucial comparison was between posttest means of Conditions 1 and 2 . The differences between mean scores were similar in the two studies $(0.41$ versus 0.37$)$. The standard deviations, however, were lower in the earlier study, whereas degrees of freedom were higher. This may explain why $p$ amounted to .03 in the earlier experiment and reached only the marginal value of .092 in this experiment. Still, it is felt that the results of the present study support the earlier conclusion that positively toned pretest statements may function to counteract the development of negative feelings. It may be added, however, that the effect size was quite small. Calculation of the estimated omega squared indicated only a weak degree of association. In the earlier study the $t$ value obtained between Conditions 1 and 2 accounted for $4 \%$ of the variance and in this study for only 1\%. Stated differently, in predicting posttest scores, knowledge of pretest scores resulted in only a trivial improvement.

On the basis of the present study, it may be concluded that the sensitization effect of the positive pretest is small and is restricted to item content. Comparison of posttest means of Conditions 1 and 5 showed that a pretest dissimilar to the posttest eliminates the sensitizing effect of a set of positive statements. However, identical pretest and posttest measures are frequently used in attitude change research.

The outcome of both this experiment and the earlier experiment imply that using measures prior to the treatment necessitates proper pre- 
cautions to control or to eliminate biasing pretest effects. Cowan and Komorita (1971) suggested separating the pretest phase from the posttest phase by embedding the pretest among other measures, by spacing pretest and treatment, and by using different experimenters for pretest and treatment.

Another alternative to the pretest questionnaire technique is to use nonreactive measures. As stated by Lana (1969), however, the unobtrusive measures given by Webb, Campbell, Schwartz, and Sechrest (1966) “... are rarely relevant to the research of a good many psychologists who use some sort of pretest measure" (p. 139). A third possibility is to use research designs that control for this effect. Solomon's four-group design, of course, is an excellent example (Solomon, 1949). Finally, using designs without pretests could more often be considered. If the number of subjects is reasonably large, there is no reason to doubt the efficacy of randomization.

\section{References}

Christensen, L.B. Experimental methodology. Boston: Allyn \& Bacon, 1977.
Cowan, G., \& Komorita, S.S. The effects of forewarning and pretesting on attitude change. Educational and Psychological Measurement, 1971, 31, 431-439.

Hoogstraten, J. Pretesting as determinant of attitude change in evaluation research. Applied Psychological Measurement, 1979, 3, 25-30.

Lana, R.E. Pretest sensitization. In R. Rosenthal \& R.L. Rosnow (Eds.), Artifact in behavioral research. New York: Academic Press, 1969.

Solomon, R.L. An extension of control group design. Psychological Bulletin, 1949, 46, 137-150.

Webb. E.J., Campbell, D.T., Schwartz, R.D., \& Sechrest, L. Unobtrusive measures: Nonreactive research in the social sciences. Chicago: Rand McNally, 1966.

\section{Acknowledgments}

I thank Prof. F.N. Kerlinger for his comments on an earlier draft of the manuscript.

\section{Anthor's Addreas}

Send requests for reprints or further information to Joh. Hoogstraten, Weesperplein 8, Psychological Laboratorium, Universiteit van Amsterdam, The Netherlands. 